\title{
Historic overview of treatment techniques for rib fractures and flail chest
}

\author{
M. Bemelman • M. Poeze $\cdot$ T. J. Blokhuis • \\ L. P. H. Leenen
}

Received: 16 June 2010/Accepted: 19 August 2010/Published online: 23 September 2010

(C) The Author(s) 2010. This article is published with open access at Springerlink.com

\begin{abstract}
Introduction From the beginning of the twentieth century till the current time, an overview is presented of the surgical treatment for rib fractures and flail chest.

Methods Many techniques have been used to stabilize the thorax wall. There has been no follow-up for the most described techniques and the evidence provided is at its best at L3-4. This, together with the noninvasiveness of mechanical ventilation, has made the latter the golden standard.

Conclusion However, the recent introduction of better and fully dedicated materials provides the possibility of exploring the surgical treatment of chest injuries. The authors make a case for operative treatment of rib fractures and flail chest.
\end{abstract}

Keywords Thoracic trauma - Rib fractures - Flail chest . History

\section{Introduction}

The history of the application of different treatment techniques for rib fractures mimics the movement of a pendulum. After considerable attention in the 1950s and 1960s, it

M. Bemelman - T. J. Blokhuis - L. P. H. Leenen

Department of Trauma Surgery, University Medical Center,

Utrecht, The Netherlands

M. Poeze

Department of Trauma Surgery, Maastricht University Medical Center, Maastricht, The Netherlands

M. Bemelman ( $\square)$

Department of Traumatology, University Medical Center,

Suite: G04.228, Heidelberglaan 100, 3584 CX Utrecht,

The Netherlands

e-mail: m.bemelman@umcutrecht.nl gradually lost focus until the introduction of plate systems in the 1980s. Thereafter, it again lost interest until the recent introduction of new dedicated materials, initiating a renaissance in the surgical therapy of rib fractures. In the older literature on chest injury, there is a surprisingly good understanding of injury patterns related to chest injury. Current concepts do not differ much from those of 50 years ago. The flail chest as we know it today was described as early as 1955 by Cohen [8]. The synonym "stove in chest" was used earlier, and was first described in 1945 by Hagen [22]. A specific type of flail chest called the "steering wheel injury" chest was described in 1949 by Heroy [23]. This typical injury gained increasing attention due to the evergrowing use of automobiles. The injury was the result of a head-on collision, and was due to the lack of seatbelt restraints such that the casualty smashed into the steering wheel and fractured a series of ribs bilateral to the sternum. A flail chest of the sternum segment or a "floating sternum" was the result. Physiological disturbances of the respiration related to these injuries are described in a surprisingly accurate manner. The typical paradoxical movement with decreased lung compliancy and the increased lung resistance that results in increased breathing effort are described in great detail. Moreover, the impaired venous return due to pressure changes within the chest is described [2, 15]. Williams describes a typical clinical triad related to flail chest: intrabronchial hemorrhage, ineffectual cough and typical anoxia [44]. These early reports feed a progressive awareness that patients with flail chest have a poor prognosis; a high mortality rate of up to $80 \%$ is reported $[16,23$, 36], leading to numerous ideas and techniques for the chest. Upon analyzing these techniques, they can be divided into two main groups: internal support techniques and external support techniques. The latter group can be divided into conservative, percutaneous and invasive therapies. 


\section{Internal support}

Internal support or splinting by mechanical positive pressure ventilation is in fact a relatively modern technique compared to external splinting.

Even though the first description of artificial respiration was provided in 1902 by Hoyt [24], it was another 49 years before it achieved clinical use. The first publication that deals with positive pressure ventilation for chest injury was from Carter et al. [6]. They describe a technique in which they employ tracheostomy together with intermittent positive pressure ventilation. This method is based on the idea that a tracheotomy enables adequate removal of retained secretions and intermittent mechanical ventilation gives internal support to the lungs and decreases the physical demands on the respiratory muscles.

Avery et al. [1] was the first to describe continuous mechanical ventilation, thus providing permanent internal pneumatic stabilization for chest injury.

Garzon [15] was one of the first to discuss the use of a tracheostomy combined with continuous mechanical ventilation. He analyzed a group of 12 patients with flail chest. Nine received tracheotomies and eight mechanical ventilation. As many as four of these 12 patients died as a result of their injuries. The author describes in great detail the pathophysiology of the lung. He proves a relation between lung compliance, airway resistance, breathing workload, lung volumes, pulmonary diffusion, blood gases, shunting, and the extent of the injury.

In the same year, Baumann [2] published a comparable manuscript dealing with three therapeutic modalities: (1) continued mechanical ventilation with endotracheal intubation; (2) ventilation with a tracheotomy, and; (3) intermittent assisted breathing with a mouth piece. He also describes in great detail the relation between the injury, lung capacity, therapy and blood gases. In another report from a surgical nurse, Prentice [35], a patient with serious chest injury and flail chest who was treated with a Bennett ${ }^{\circledR}$ respirator for 14 days was described (Fig. 1).

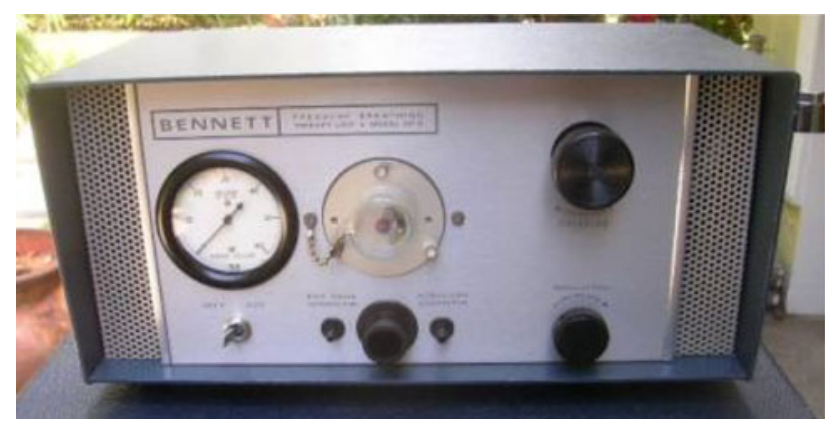

Fig. 1 Bennet ${ }^{\circledR}$ respirator. Reproduced with the permission of Jeff Weisman

\section{External support}

The first report of external support for a flail chest was from Jones [27]. This appeared 25 years before mechanical ventilation was presented.

Jones describes a percutaneous technique in which traction is applied to the ribs with bullet forceps. After this first report, many alternative techniques for percutaneous traction on the rib cage were described. A better understanding of different injury patterns evoked different therapy strategies. Heroy [23] published the first manuscript in which a surgical technique to stabilize chest injuries after "steering wheel injury" was described. The authors acknowledge the seriousness of severe chest injury, and specifically the paradoxical movements of the chest with flail chests. The author describes three different patterns of flail chest, with a tailor-made therapy for each. The relative simple lateral flail chest was treated with nonoperative methods like strapping and "sandbagging," the latter meaning nothing more than pressing sandbags against the chest at the discretion of the patient. The typical "steering wheel injury" chest was stabilized with a clamp in the sternum, which was held under traction. The more stable posterior flail chest was treated with the so-called Drinker ${ }^{\circledR}$ respirator [23] (Fig. 2).

\section{External support: nonoperative}

The simplest of the reported nonoperative measures is strapping the chest with adhesive tape. The first publications concerning this were from Berry et al. [4, 11, 22]. Hagen [22] was the first to describe a form of respiratory support with the Drinker respirator (also known as the "iron lung"). This technique uses external splinting, as the working motion of this device is based on a repetitive cycle of creating a vacuum in a metal cylinder and subsequently

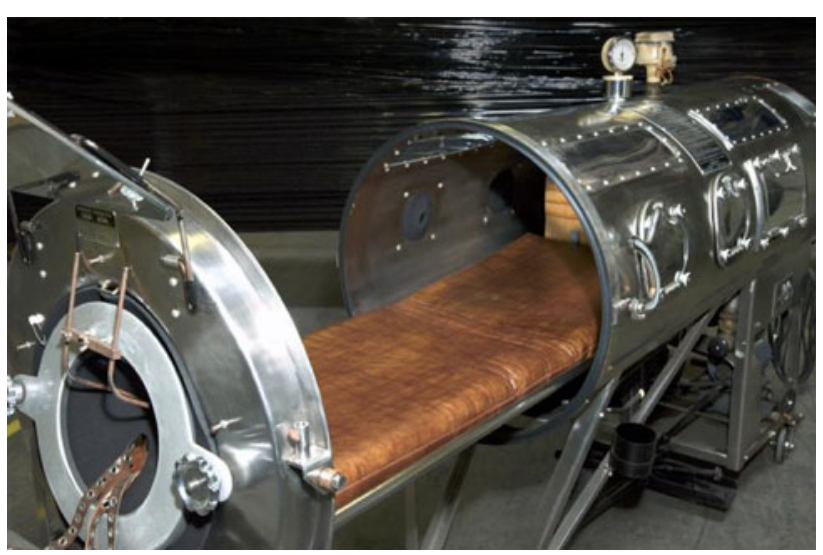

Fig. 2 Drinker ${ }^{\circledR}$ respirator. The patient would be positioned in the cylinder with their head inserted through a metal plate with a rubber seal. From http://commons.wikimedia.org (free of copyright) 
transferring it to the chest wall of the patient, thus creating inspiration cycles. The patient was positioned in the cylinder for a period of 10 days and weaned for another 11 days.

Schrire [39] describes a large rubber suction device called the Cape Town Limpet that was analogous to a sink plunger. This contraption was applied to the flail segment and subsequently put under traction (Fig. 3).

\section{External support: percutaneous}

Jones [27] described the first successful treatment using percutaneous external support in a child. This child had eight unilateral rib fractures, which were treated with traction applied with bullet forceps (Fig. 4).

Jaslow [26] describes a rather bizarre but ingenious technique. Patients with a sternum flail chest were stabilized through the introduction of a clothes hanger hook in the sternum. He selected a wooden clothes hanger with a threaded metal hook. A small incision on the sternum, performed under local anesthetic, enabled him to drill a small hole and subsequently insert the hook in the sternum. In order to avoid penetrating the posterior cortex, he calculated that turning the hook five times would be sufficient and safe. The hook was subsequently connected to a weight, creating a form of suspension. The patient was left

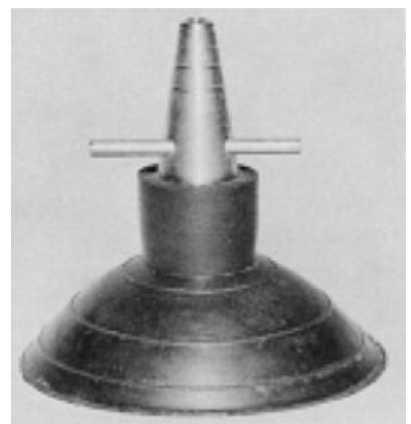

Fig. 3 The "Cape Town Limpet" is analogous to a normal sink plunger. Vacuum is created through the metal tube, which is then sealed. Traction is then applied by pulling on the metal bar. Reproduced from [39] with permission

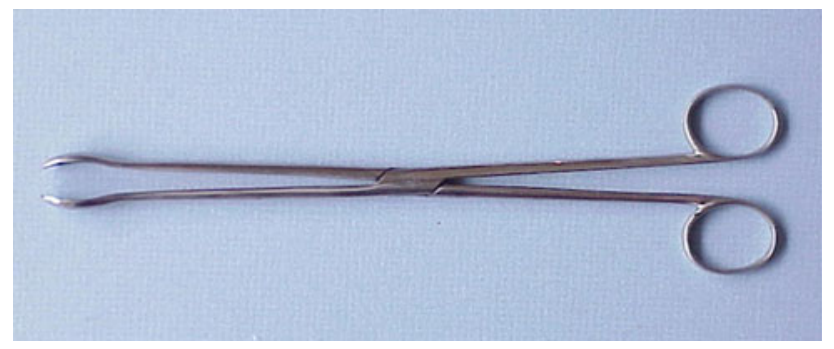

Fig. 4 Bullet forceps

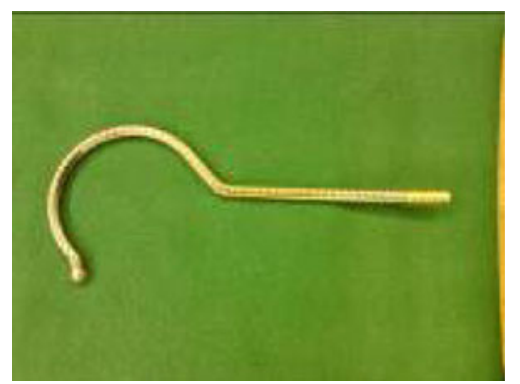

Fig. 5 Hook from an ordinary clothes hanger

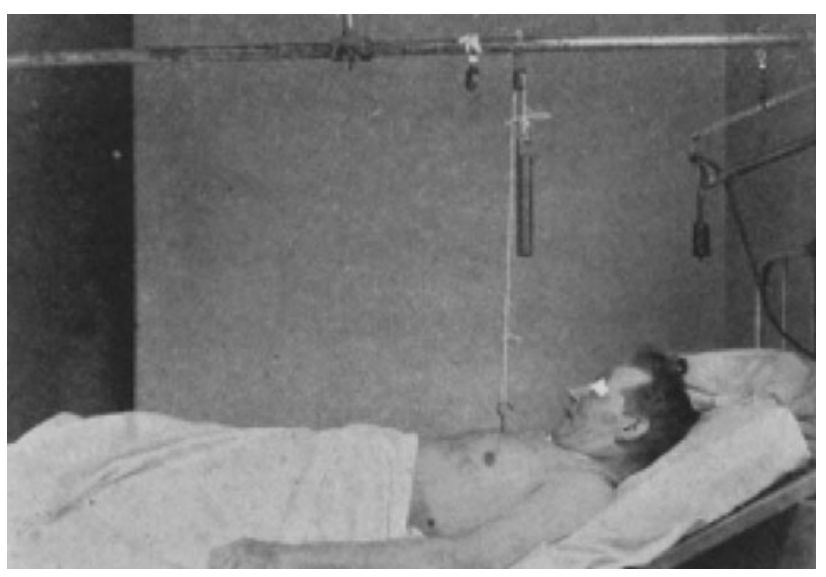

Fig. 6 Patient with the hook placed in the sternum and traction applied. Note that the weight is hanging above the patient; imagine the rope breaking or the hook being pulled out! Reproduced from [26] with permission

like this for eight days. Jaslow did not realize this, but he may have invented the first variant of a Schanz screw (Figs. 5, 6).

Heroy [23] treated flail chest with different techniques. In the case of a steering wheel injury, they applied vitallium alloy screws in the sternum and then applied traction with the patient in the high Fowler's position. This situation would last for approximately $24 \mathrm{~h}$, after which the screws would generally break out.

They would then commence with the next step: introducing reduction forceps into the two screw holes and applying $10 \mathrm{lb}$ of traction for 17 days (Fig. 7).

Many alternative traction or suspension principles have been described. Some are similar to towel clips or forceps [44]; others use different techniques, like metal wires around the ribs [14], and some are even more bizarre, like the placement of a corkscrew in the sternum [23].

Another ingenious instrument was invented by the Hungarian surgeon Constantinescu and published in 1965 [9]. He designed a sharp $90^{\circ}$ hook that could fold open when situated in the chest, forming a $\mathrm{T}$ shape. This enabled him to create traction by subsequently placing a plate on the outside and thus stabilizing the chest (Figs. 8, 9]. 


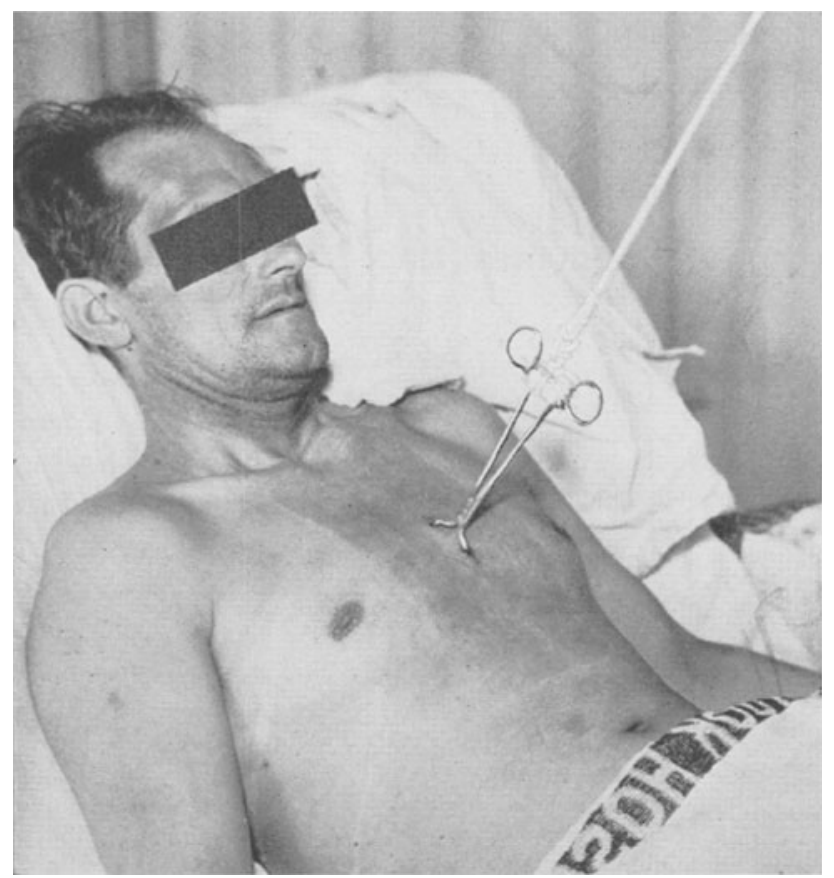

Fig. 7 Patient with traction applied to the sternum after placing reduction forceps. Reproduced from [23] with permission

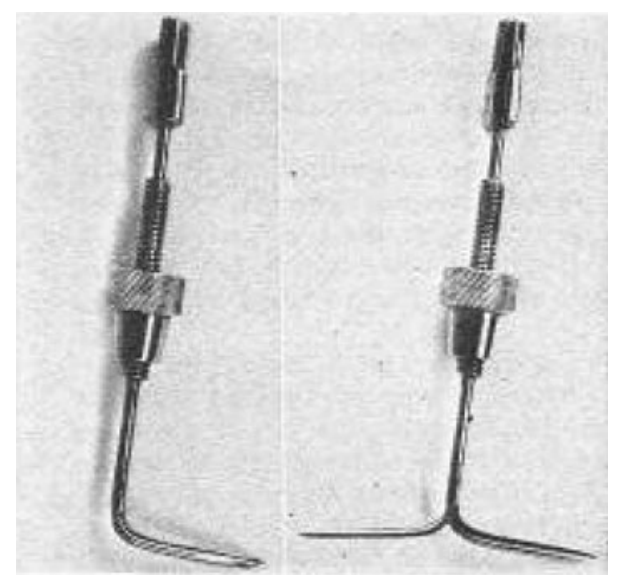

Fig. 8 Troicart bent at a $90^{\circ}$ angle; a T shape is formed after twisting one half

The basic idea behind all of the techniques mentioned here was that traction would lead to the expansion of the lung tissue, thus creating a larger vital capacity for the lungs with less resistance and a reduced risk of atelectasis, pneumonia and respiratory failure. Moreover, stabilizing the chest would reduce the pain, leading to more comfort.

In 1996, an interesting article was published by Gyhra et al. [21]. The authors present the results of a study comparing two different external stabilizing techniques. Adhesive strapping and sandbagging was used in one group, and percutaneous traction through towel clips in the other. It is intriguing to read that old techniques were still being used in 1996, and even being investigated in a comparative study. The results not surprisingly show that the latter had better respiratory parameters.

External support by operative means

Invasive techniques for rib fractures and flail chest developed in parallel with the percutaneous techniques. One of the first publications in this area was from Hagen and Elkin $[13,22]$. They describe a technique in which the depressed fractures are fixed with wires or sutures after open reduction. We can subdivide invasive techniques into two subgroups:

1. Invasive suspension

2. Open reduction and internal fixation (ORIF).

\section{Suspension}

Aside from techniques in which anatomical reduction is the goal, many techniques for attaining some sort of internal suspension of the ribs have been described. It is notable that these techniques developed later, possibly due to an increasing awareness that these patients had sustained serious injuries, and each subsequent surgical insult should be either avoided or shortened where possible. The first publication to deal with suspension techniques after open surgery was from a French surgeon, Dor [12]. A technique is described in which the fracture of the ribs is stabilized with $\mathrm{K}$ wires.

Beltrami et al. and Guernelli et al. [3, 20] describe a technique in which the flail chest is stabilized by inserting two long $\mathrm{K}$ wires under the flail chest after an open thoracotomy.

The latter author compares his technique with barbecue skewers in a St. Andrews cross formation. After 30 days, the wires were removed, and good results were noted, albeit with no detail (Fig. 10).

In 1991, Landreneau et al. [31] described a technique in which they refer to Beltrami et al. [3]. They treat flail segments with metal struts from the Lunque ${ }^{\circledR}$ rod orthopedic external fixation device. The rods are inserted during a thoracotomy and held in place with an external coupling device. It is not clear if the device was buried subcutaneously or was above the skin. They do say that the device is removed on the ward with local anesthetic, suggesting that the coupling devices were left outside the skin (Fig. 11).

The technique used by Landreneau et al. [31] is in fact analogous to the Nussbar ${ }^{\circledR}$ technique, which was initially described and used for the repair of pectus excavatum. Glinz and Carbognani $[5,18]$ both describe techniques in which they too suspend the chest wall with a metal bar in order to treat flail chest. In 2001, Glavas described [17] a 
Fig. 9 Patient with the troicart placed intercostally and fixed under traction to a board on the patient. Reproduced from [9] with permission
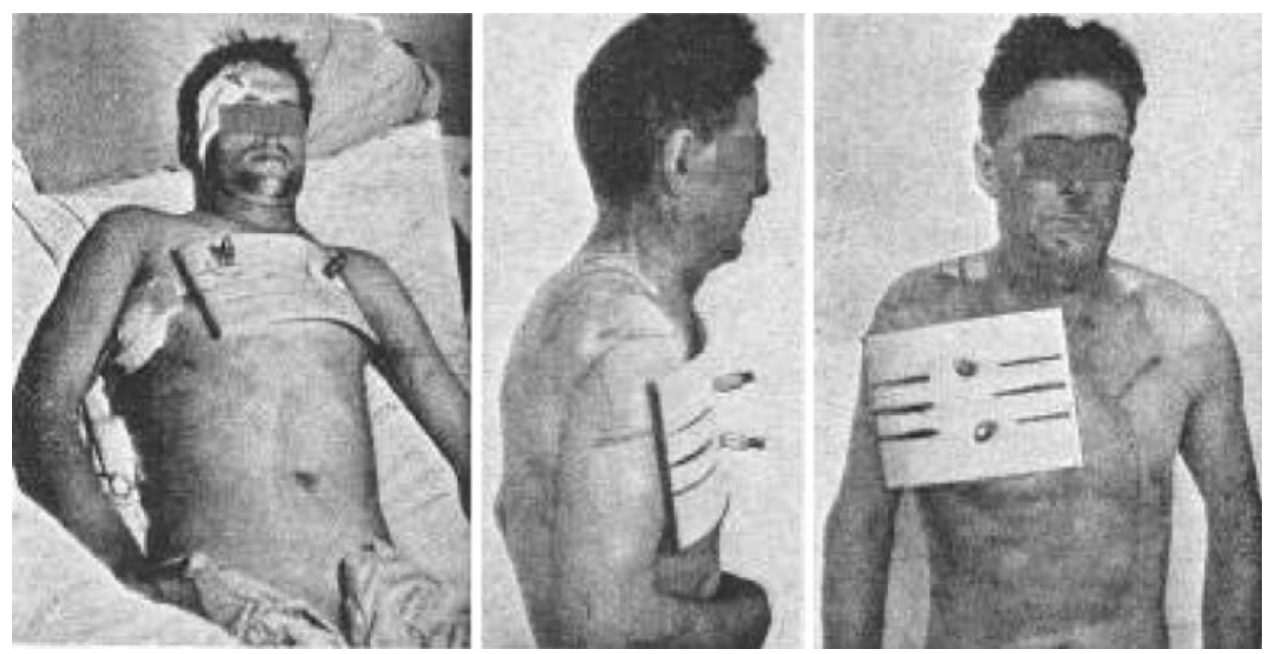

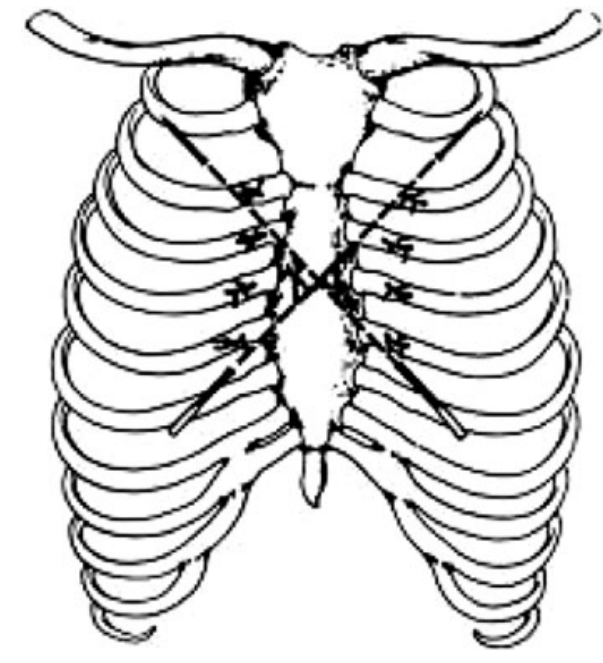

Fig. 10 Schematic drawing made by Guernelli of where he put the "skewers" in the patient. Reproduced from [20] with permission

technique in which the flail segment is bridged with a bone cement $\left(\right.$ Pallacos $\left.{ }^{\circledR}\right)$ prosthesis. The prosthesis is made inhouse and reaches from the proximal intact rib to the distal intact rib, crossing the flail segment tangentially. The ribs were attached to the prosthesis with sutures or wires. He reports the treatment of 56 patients with good results; however, no fine details are shared.

\section{ORIF}

Regardless of the material used, a similar principle was used in this group of techniques. The surgeons reduced the fracture after open reduction and subsequently created a stable fixation, creating a near-normal chest shape and physiology, and thus enabling normal respiration.

Many different devices have been described. Intramedullary devices have been described by Klassen (bone pegs) [29] and Cruther and Nolen (rush pins) [10]. Aside from

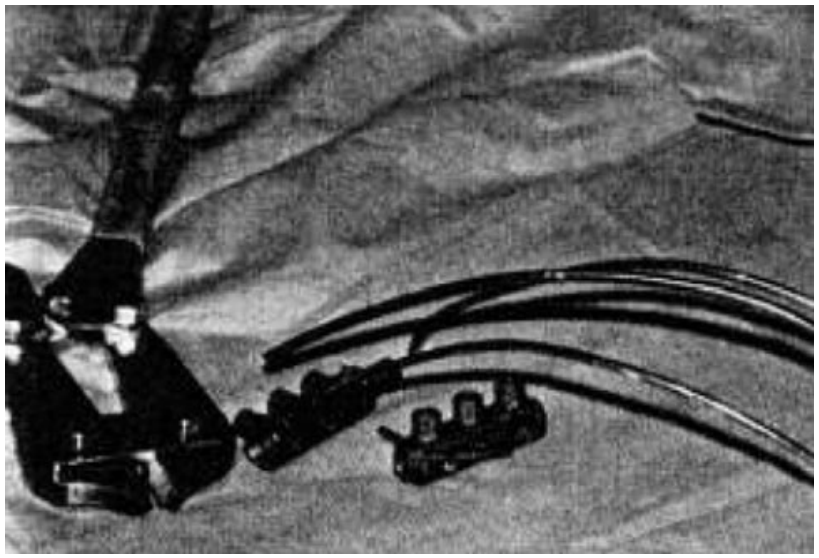

Fig. 11 Picture of the Lunque $^{\circledR}$ fixator after removal from the patient. Note the large cutter and the coupling device, which was probably positioned outside the patient. Reproduced from [31] with permission

these intramedullary techniques, many surgeons (Hagen, Elkin) $[13,22]$ have used a simple principle, suturing the fractures with either metal wires or sutures.

Of course, many techniques have employed plates, so many different plates have been designed. Sillar [40] was the first to report the use of plates to stabilize the chest. The plates were mainly used for sternum fractures; rib fractures were stabilized with parallel $\mathrm{K}$ wires through the ribs. Many authors subsequently reported improvised self-made plates and eventually plates dedicated to fixing ribs.

Paris [34] described different techniques utilizing an arsenal of self-made plates in which they suspended the fractures. He also described a technique that may be one of the first MIPO (minimal invasive plate osteosynthesis) techniques, since it involved pushing a plate through two small incisions (Figs. 12, 13).

Some plates depend on the fixation of screws to the ribs. The problem with these is that the ribs are relatively soft, so the screws are prone to breaking out of the material. In 

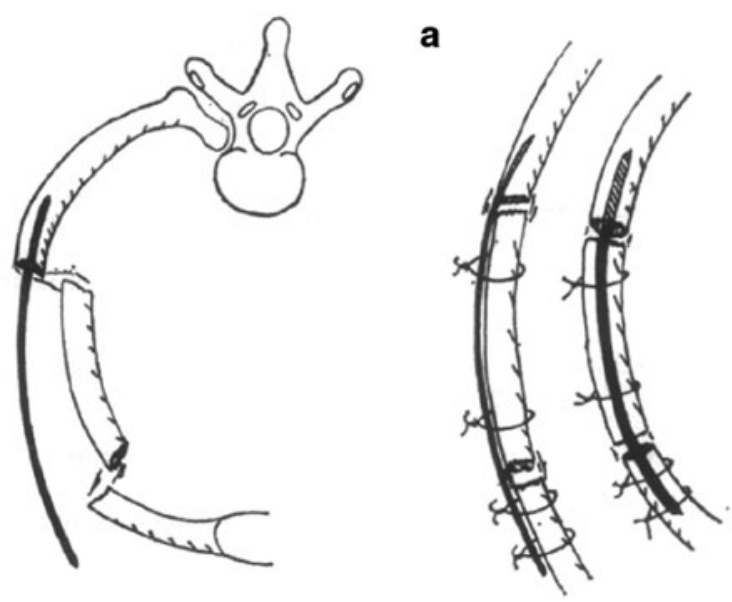

b
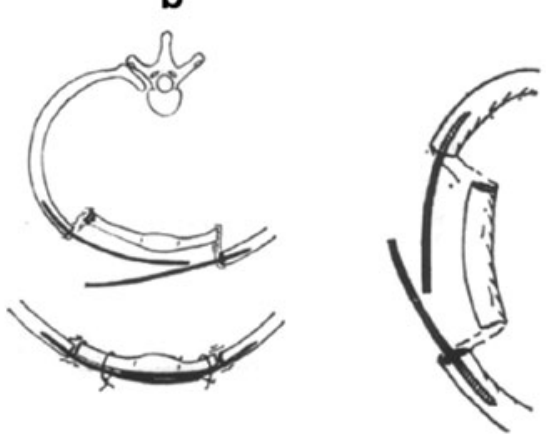

C

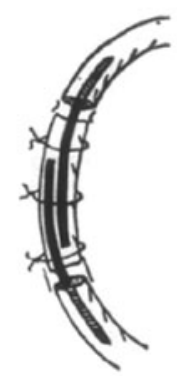

Fig. 12 Illustration from Paris showing the use of the plates. Reproduced from [34] with permission

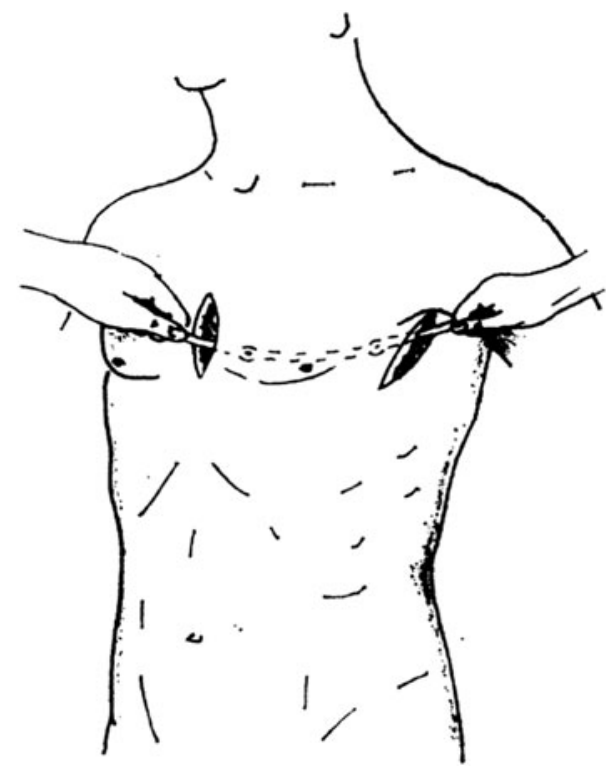

Fig. 13 Illustration from Paris showing the percutaneous placement of a plate. This could be the first illustration of a MIPO technique

1981, Labitzke [30] published an article in which he described the use of Drittelrhor plates that eventually broke out after $12 \mathrm{~h}$. This motivated him to design and develop a

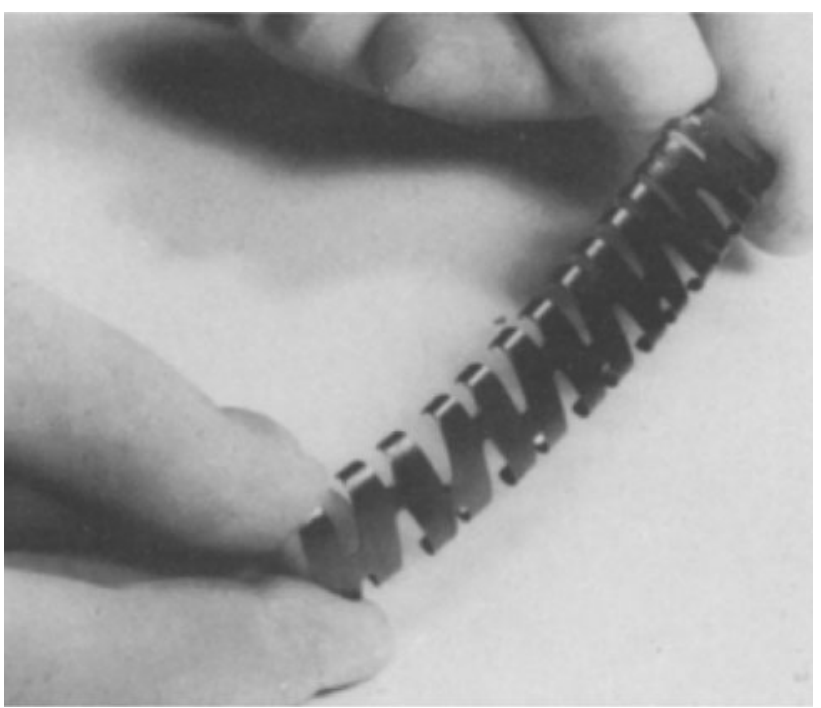

Fig. 14 The plate designed and used by Labitzke. Note the asymmetric joints between the clamps. Reproduced from [30] with permission

plate with a grasping mechanism which he then used and is thus currently known as the Labitzke plate (Fig. 14). He is probably also the first person to use titanium plates. The design of the plate is rather ingenious; because he realized that it was necessary to bend the plates in two directions, he fitted the clamps with asymmetric joints, which enabled bending in the plane of the plate (Fig. 14).

The introduction of Labitzke's plate system [30] initiates a period (the 1980s) during which there was renewed interest in rib fixation with plate systems.

Other authors present more positive reports on the use of conventional plates like the Drittelrohr [32] or AO recon plates [43]. The Judet [28] and Sanchez [38] plates are similar to the Labitzke plate. They all use the principle of grasping the relatively soft bone of the ribs with flat hooks instead of relying on screws. The idea was that this would lead to less breakout and remove the risk from drilling and subsequently perforating structures beneath the ribs (Figs. 15, 16, 17).

Sales et al. [37] published an article in which a new design of plate that uses both principles (screwing and grasping function) was described. This resulted in the $\mathrm{U}$ plate or the RibLoc $^{\circledR}$ plate from Acute Innovations ${ }^{\mathrm{TM}}$. As the name suggests, the plate takes the form of a $\mathrm{U}$ that slides over the rib; fixation is then obtained with angular stable screws.

In 2007, Vodicka [42] published a manuscript in which he describes 40 patients who were treated for ten years with Medin ${ }^{\circledR}$ plates. These plates resemble the Judet plate, as the ribs are held with hooks. The surgeon can add additional screws through the plate to obtain better fixation. The difference is that the plates are fixed onto the face of the rib instead of around the rib (Fig. 18). 


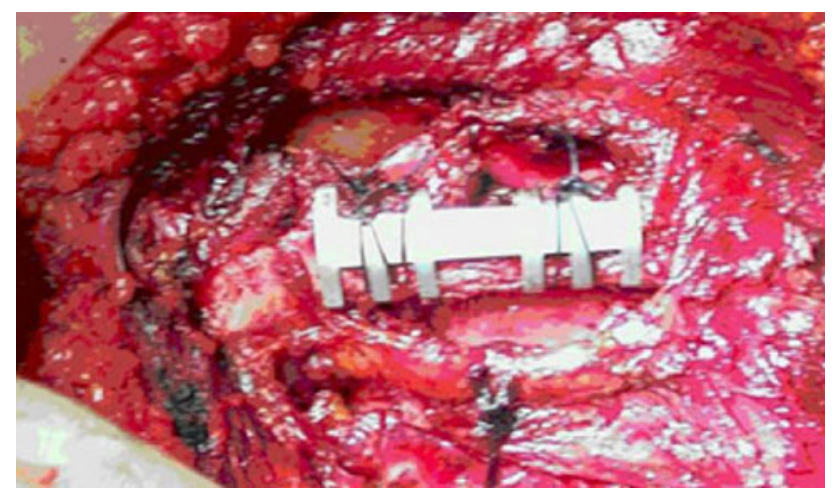

Fig. 15 Judet plate; note the use of additional sutures to hold the plate in position. Reproduced from [7] with permission

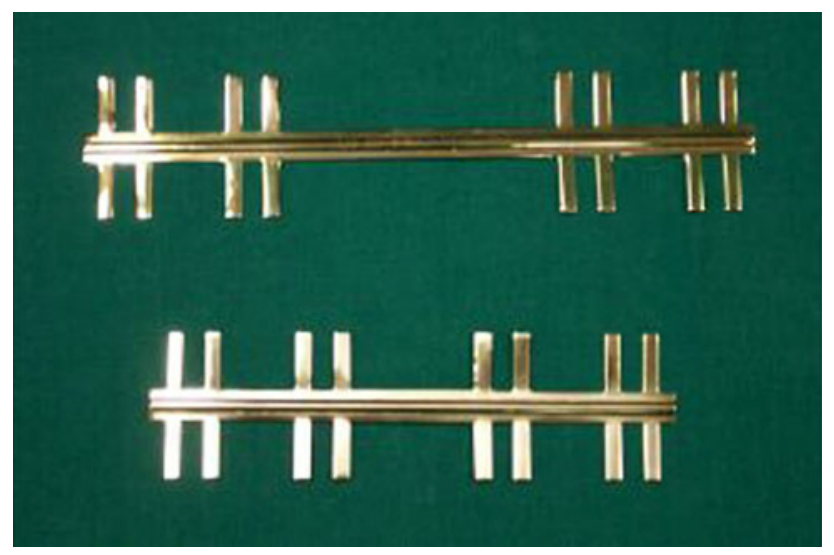

Fig. 16 Sanchez-Lloret plate. Reproduced from [7] with permission

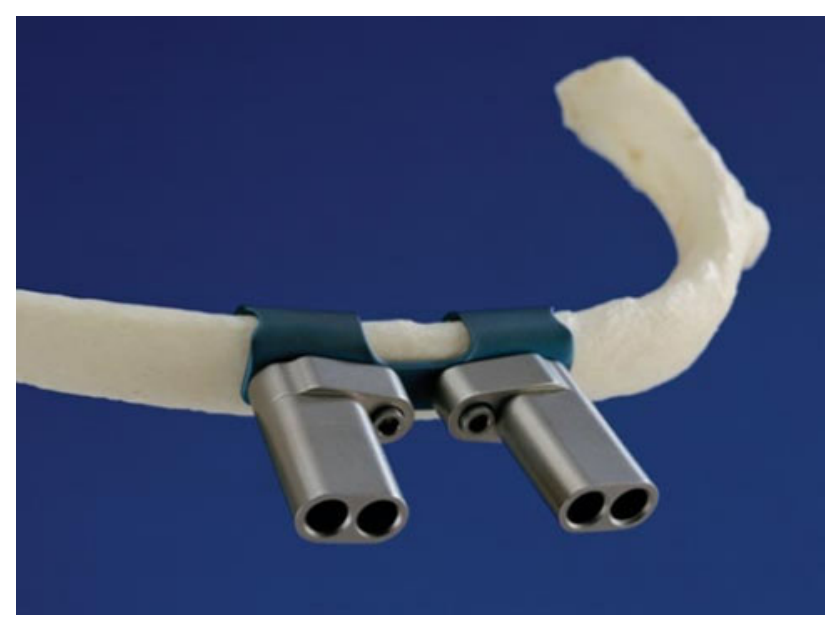

Fig. 17 The RibLoc ${ }^{\circledR}$ plate, manufactured by Acute Innovations ${ }^{\mathrm{TM}}$

In 2008 a dedicated system was introduced to the French scene. It is called the Stratos ${ }^{\circledR}$ system (an abbreviation of "Strasbourg thoracic osteosynthesis system"). It is a fully dedicated system for the treatment of rib fractures and chest wall deformities. The fixation mechanism is analogous to that for the Judet plate. The system is also equipped with bars that can be connected to the plates to bridge or suspend thoracic wall segments. No clinical results have been published thus far.

In 2009, Ivancic [25] described a technique that is based on the use of the $\mathrm{K}$ wire but augmented with a figure-ofeight cerclage wire to create more stability. This primitive and simple technique had not been published before (Fig. 19).

The most recent system was presented by Synthes ${ }^{\mathrm{TM}}$ : the Matrix ${ }^{\circledR}$ rib fixation system. It is a fully dedicated plate and splint system solely for the stabilization of ribs. The plates are made of titanium and are designed in such a manner that they mimic the biodynamic characteristics of ribs. The plates and splints are fixed with locking screws.

An interesting aspect of all of the plate systems described here is that there is very limited follow-up in the literature after the initial publication. This suggests that there may have been some problems with the systems. Labitzke describes conventional plates and screws breaking out. Just thinking about the systems and their application introduces potential problems. Labitzke's plate system with clamps is made of titanium, which has $50 \%$ recoil when trying to bend the hooks around the ribs. This may cause insufficient grip around the ribs. Furthermore, the ribs are relatively soft compared to other bones, which may make them prone to breakage when attempting to bend clamps around the ribs.

Neither of these theoretical problems exist with the two most recent systems on the market. For instance, in the RibLoc plate system from Acute Innovations, the plate, which is fabricated from titanium, slides over the ribs without the need to bend it around the rib. It is then fixed with locking screws.

\section{Discussion}

Over the years, many techniques have been used to stabilize the thorax and ribs in order to treat rib fractures and flail chest, as most authors are convinced that the treatment of these conditions is warranted. However, considering the large number of solutions proposed, no definitive solution has been presented yet. Upon reviewing conservative external techniques like strapping or "sand bagging," it quickly becomes obvious that these techniques were not sufficient. Some simple studies tried to prove this, but if we consider current "evidence-based rules," none of these studies get above level 3-4.

The summary of invasive techniques provided here highlights the ingenuity of the treating surgeons. Contraptions range from the relatively simple and apparently effective to the bizarre and potentially dangerous. Most of 
Fig. 18 Medin ${ }^{\circledR}$ plates. Reproduced from [42] with permission
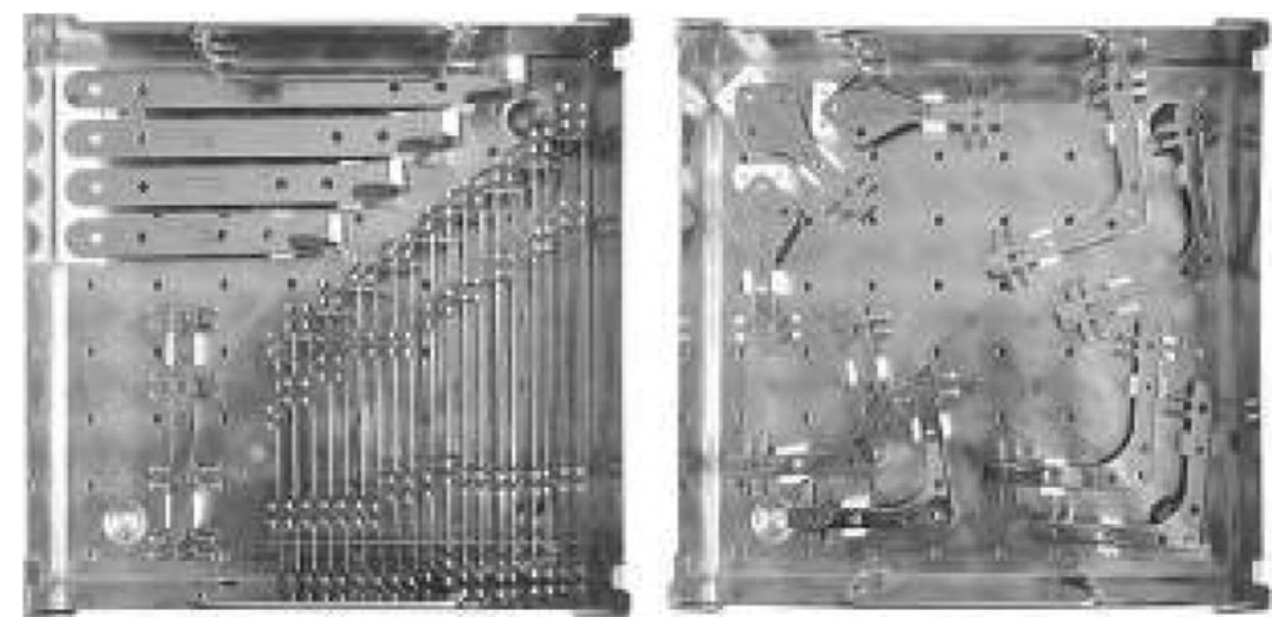

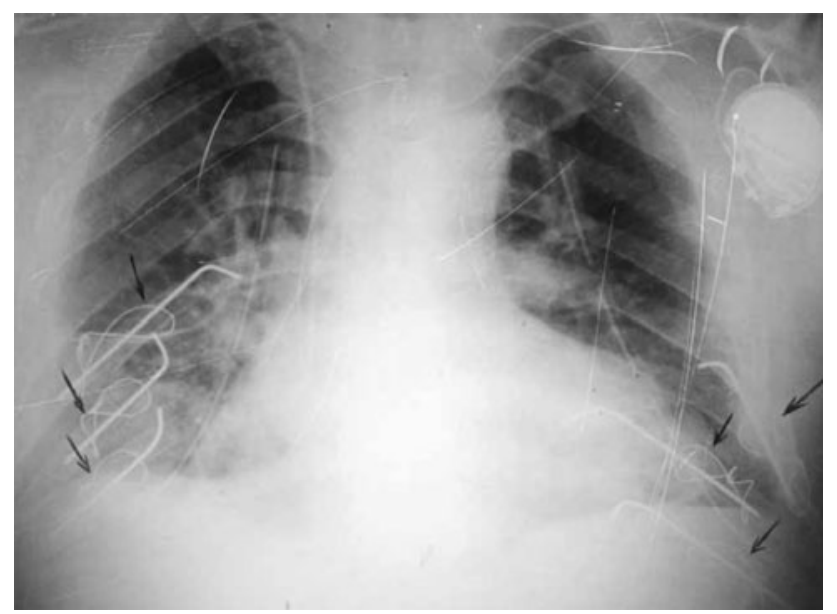

Fig. 19 Chest $\mathrm{X}$-ray with the $\mathrm{K}$ wires and cerclage in situ. Reproduced from [25] with permission

the manuscripts provide no details about any complications, but considering the proposed methods, we would expect them to lead to serious complications like empyema, lung injury, cardiac injury, etc. The fact that none of these techniques has become widely popular confirms that probably all of these expected complications occurred. This has most probably contributed to the popularity of mechanical ventilation as the most popular means of treating thoracic trauma with serial rib fractures, flail chest and pulmonary contusion. This is still seen as the most reliable technique, and remains the gold standard even today. Nevertheless, given recent studies like that of Tanaka et al. [41], it appears that we can still improve our therapy regimes for rib fractures and flail chest, especially with the introduction of fully dedicated osteosynthesis materials for flail chest and rib fractures.

That these plate systems may offer better therapeutic solutions for flail chest and rib fractures is suggested by recent studies done by Graznetsky et al. [19, 33, 41]. These studies prove (level 2-3) that operative treatment of flail chest leads to a shorter ICU stay, fewer cases of pneumonia and reduced mortality compared to ventilatory support.

\section{Conflict of interest None.}

Open Access This article is distributed under the terms of the Creative Commons Attribution Noncommercial License which permits any noncommercial use, distribution, and reproduction in any medium, provided the original author(s) and source are credited.

\section{References}

1. Avery E, Morch E, Head J, Benson D. Severe crushing injuries of the chest; a new method of treatment with continuous hyperventilation by means of intermittent positive endotracheal insufflation. Q Bull Northwest Univ Med Sch. 1955;29(4):301-3.

2. Baumann J, Stieglitz P, Desmonts JM, Drutel P, Poyart C. Traitement des volets thoraciques. Ann Chir Thor Car. 1967;6(1): $43-52$.

3. Beltrami V, Martinelli G, Giansante P, Gentile K. An original technique for surgical stabilisation of traumatic flail chest. Thorax. 1978;33:528-9.

4. Berry F. Treatment of injuries to the chest. Am J Surg. 1941;54:280.

5. Carbognani P, Cattelani L, Bellini G, Rusca M. A technical proposal for the complex flail chest. Ann Thorac Surg. 2000;70: 335-43.

6. Carter BM, Giuseffi J. Tracheostoma a useful operation in thoracic surgery with particular references to its employment in crushing injuries of the thorax. J Thorac Surg. 1951;21:495.

7. Casali C, Fontana G, Morandi U. Surgical stabilization of severe flail chest. http://www.ctsnet.org/sections/clinicalresources/ thoracic/expert_tech-24.html.

8. Cohen EA. Treatment of the flail chest by towel clip traction. Am J Surg. 1955;90(3):517-21.

9. Constantinescu O. A new method of treating the flail chest wall. Am J Surg. 1965;109:604-10.

10. Crutcher R, Nolen T. Multiple rib fracture with instability of chest wall. J Thorac Surg. 1956;32(1):15-21.

11. DeBakey M. Management of chest wounds, collective review. Surg Gynec Obstet. 1942;74:202.

12. Dor V, Paoli J, Noirclerc M, Malmejac C, Chauvin G, Pons R. Lósteosynthese des volets thoraciques technique, resultants et indications a propos de 19 observations. Ann Chir. 1967;21:983-96. 
13. Elkin D, Cooper F. Thoracic injuries: review of cases. Surg Gynec Obstet. 1943;72:271.

14. Gardner C. Chest injuries. Surg Clin N Am. 1946;26:1082.

15. Garzon A, Seltzer B, Karlson K. Physiopathology of crushed chest injuries. Ann Surg. 1968;168(1):128-36.

16. Ginsberg R, Kostin R. 5 New approaches to the management of flail chest. Can Med Assoc J. 1977;116(6):613-5.

17. Glavas M, Altarac S, Vukas D, Ivancić A, Drazinić I, Gusić N, Celović R, Mirković I. Flail chest stabilization with palacos prosthesis. Acta Med Croatica. 2001;55(2):91-5.

18. Glinz W. Problems caused by the unstable thoracic wall and by cardiac injury due to blunt injury. Injury. 1986;17:322-6.

19. Granetzny A, Abd El-Aal M, Emam E, Shalaby A, Boseila A. Surgical versus conservative treatment of flail chest. Evaluation of the pulmonary status. Interact Cardiovasc Thorac Surg. 2005; 4:583-7.

20. Guernelli N, Bragaglia R, Briccoli A, Mastrorilli M, Vecchi R. Technique for the management of anterior flail chest. Thorax. 1979;34:247-8.

21. Gyhra A, Torres P, Pino J, Palacios S, Cid L. Experimental flail chest: ventilatory function with fixation of flail segment in internal and external position. J Trauma 1996;40(6):977-9.

22. Hagen K. Multiple rib fractures treated with a drinker respirator: a case report. JBJS Am. 1945;27(2):330-4.

23. Heroy WW, Eggleston FC. A method of skeletal traction applied through the sternum in "steering wheel injuries of the chest." Ann Surg. 1951;133:127.

24. Hoyt J. An apparatus for artificial respiration and for other purposes. J Physiol. 1902;27:48-52.

25. Ivancic A, Saftic I, Cicvaric T, Spanjol J, Stalekar H, Marinovic M, Markic D. Initial experience with external thoracic stabilization by the "figure of eight" osteosynthesis in polytraumatized patients with flail chest injury. Coll Antropol. 2009;33(1):51-6.

26. Jaslow I. Skeletal traction in the treatment of multiple fractures of the thoracic cage. Am J Surg. 1946;72(5):753-5.

27. Jones T, Richardson E. Traction on the sternum in the treatment of multiple fractured ribs. Surg Gynec Obstet. 1926;42:283.

28. Judet R. Osteosynthese costale. Rev Chir Orthop. 1973;59(1): $334-5$.

29. Klassen KP. Medullary pegging in thoracotomy incisions. J Thorac Surg. 1949;18(1):90-6.
30. Labitzke R, Schmit-Neuerburg K, Schramm G. Indikation zur thoracotomie und rippenstabilisierung beim thoraxtrauma im hohen lebensalter. Chirurg. 1980;51:567-80.

31. Landreneau R, Hinson J, Hazelrigg S, Johnson J, Boley T, Curti J. Strut fixation of an extensive flail chest. Ann Thorac Surg. 1991;51:473-5.

32. Lindenmaier H, Kuner E, Walz H. Operative treatment of the instability of thorax. Unfallchirurgie. 1990;16(4):172-7.

33. Nirula R, Diaz J, Trunkey D, Mayberry J. Rib fracture repair: Indications, technical issues, and future directions. World J Surg. 2009;33:14-22.

34. Paris F, Tarazona V, Blasco E, Canto A, Casillas M, Pastor J, Paris M, Montero R. Surgical stabilization of traumatic flail chest. Thorax. 1975;30:521-7.

35. Prentice G. Crush injuries of the chest. Nurs Times. 1967;7: 451-3.

36. Relihan M, Litwin M. Morbidity and mortality associated with flail chest injury: a review of 85 cases. J Trauma. 1973;13(8): 663-71.

37. Sales JR, Ellis TJ, Gillard J, Liu Q, Chen JC, Ham B, Mayberry JC. Biomechanical testing of a novel, minimally invasive rib fracture plating system. J Trauma. 2008;64(5):1270-4.

38. Sanchez-Lloret J, Letang E, Calleja MA, Canalis E. Indication and surgical treatment of the traumatic flail chest syndrome: an original technique. Thorac Cardiovasc Surg. 1982;30:294-7.

39. Schrire T. Control of the crushed chest: the use of the "Cape Town Limpet." Dis Chest. 1963;44:141-5.

40. Sillar W. The crushed chest. JBJS. 1961;43B(4):738-45.

41. Tanaka H, Yukioka T, Yamaguti Y, Shimizu S, Goto H, Matsuda $\mathrm{H}$, Shimazaki S. Surgical stabilization of internal pneumatic stabilization? A prospective randomized study of the management of severe flail chest patients. J Trauma. 2002;52(4):727-32.

42. Vodicka J, Spidlen V, Safranek J, Simanek V, Altmann P. Severe injury to the chest wall-experience with Surgical therapy. Zentralbl Chir. 2007;132:542-6.

43. Voggenreiter G, Neudeck F, Aufmkolk M, Obertacke U, SchmitNeuerburg K. Behandlungsergebnisse der operativen thoraxwandstabilisierung bei instabilem thorax mit und ohne lungenkontusion. Unfallchirurg. 1996;99:425-34.

44. Williams M. Severe crushing injury to the chest. Ann Surg. 1948;128(5):1006-11. 